\title{
Fuzzy Control of a Large Crane Structure
}

\author{
Samir A. Farag ${ }^{1^{*}}$, Salah G. Foda ${ }^{2}$, and Ahmed Alenany ${ }^{3}$ \\ ${ }^{1}$ Department of Electrical and computer Engineering, Higher Technological Institute (H.T.I), 10th of \\ Ramadan, Egypt. \\ ${ }^{2}$ Department of Mechanical Engineering, Future University (F.U.E), Egypt. \\ ${ }^{3}$ Department of Computers and Systems Engineering, Zagazig University, Egypt. \\ e-mail: samir.harb22@yahoo.com*, salah.foda@fue.edu.eg, alenany102@hotmail.com
}

\begin{abstract}
The usage of tower cranes, one type of rotary cranes, is common in many industrial structures, e.g., shipyards, factories, etc. With the size of these cranes becoming larger and the motion expected to be faster and has no prescribed path, their manual operation becomes difficult and hence, automatic closed-loop control schemes are very important in the operation of rotary crane. In this paper, the plant of concern is a tower crane consists of a rotatable jib that carries a trolley which is capable of traveling over the length of the jib. There is a pendulum-like end line attached to the trolley through a cable of variable length. A fuzzy logic controller with various types of membership functions is implemented for controlling the position of the trolley and damping the load oscillations. It consists of two main types of controllers radial and rotational each of two fuzzy inference engines (FIEs). The radial controller is used to control the trolley position and the rotational is used for damping the load oscillations. Computer simulations are used to verify the performance of the controller. The results from the simulations show the effectiveness of the method in the control of tower crane keeping load swings small at the end of motion.
\end{abstract}

Keywords: fuzzy control, crane structure, controller, fuzzy inference engines (FIEs).

\section{Introduction}

A crane is a specific machine that is equipped with chains or wires, and sheaves and used for transportation of heavy loads and hazardous materials in factories, shipyards, highbuilding construction, and nuclear installations. The main task of crane in industry is to move a load from one point to another without swinging (minimum swing as possible) in the minimum time. Doing this task needs a skillful operator using his/her experience to immediately stop the swing at the right position and the operator has to wait until the load stops swinging. The failure in controlling crane might also cause accident and harm people. During the crane operation, the load - held by crane - is free to swing in a pendulum-like pattern. The nonlinear properties of crane bring about undesired swings, especially at take-off and arrival. Such uncontrolled swings cause both stability and safety problems. If these swings exceed the allowable limits, there will be two options; which are damping the swings or stopping the operation until the swings die out. Either of the two options consumes time, and hence reduces the facility availability [1].

The aforementioned problems have motivated many researchers to develop control approaches to automate cranes. However, two problems arise in automation of crane operations. Firstly, cranes belong to a class of under-actuated/under-constrained mechanical systems, i.e., in which the number of control input/outputs is fewer than degrees of freedom. In other words, a limited number of inputs control more outputs. Secondly, the unstructured nature of the crane environment in factory floors, shipyards...etc. So, the control algorithm should be able to cope with these problems. Enormous controlling approaches were implemented for controlling cranes systems based on open-loop and closed-loop control systems [3, 6, 10, 14]. Approaches to control the crane operations can be summarized as follows.

\subsection{Open-loop controllers}

An early used approach of open loop controller utilizes the natural frequency of the suspended object in presenting an open-loop-optimal-programmed control strategy. This means damping vibrations with the aid of a specific case from a general control technique involving shaping of inputs [2, 8]. 
Also, bringing the load to settle at the end point of a predefined motion profile presented using multiple input shaping techniques; using a numerical optimization process to generate parameters describing the jib angular acceleration profile and dynamic programming method algorithms to calculate the input acceleration to the jib motor. However, these techniques couldn't reduce oscillations developed less than $10^{\circ}[1,2,10,11]$.

An approach that generates crane commands which minimize the swings of the payload without a priori knowledge of the desired maneuver. The strategy depended basically on using a notch filter (based on filtering the input signal commanded by the operator, i.e., forward path velocity commands of the jib rotation speed and trolley speed) to eliminate the components of the slew and travel inputs that happen to be at the natural frequency of the payload pendulum. They designed the filter based on assuming that the trolley position was constant over each finite length period. Although the experimental results showed a reduction in load swings throughout the load transportation (a decrease in the residual oscillation magnitude in excess of $40 \mathrm{~dB}$ ), there were two problems in this approach. First, a delay of up to 2.4 seconds occurred between the operator input (unfiltered input) and the actual input (filtered input) from the filter to the crane (the noticeable delay between filtered and unfiltered motion in the jib rotation and trolley position due to the notch filtering). This delay produced in this approach leads to inconvenience to the operator and it could also cause confusion in case of accidental inputs. Second, the roll off factor of the filter had to be computed each time the cable length is changed because the notch filter is dependent on the length of the hoisting cable [1]-[12].

\subsection{Closed-loop controllers:}

Due to the well-known disadvantages of open-loop control, the previous approaches are inefficient in the presence of external disturbances and model uncertainty. Therefore, several efforts have been suggested using closed loop control. For example, in [8] the task of gantry crane control was facilitated by distributing the controlling action over two main controllers (each controller deals with few certain variables instead of all variables at once). Each controller consists of two sub-controllers (or fuzzy inference engines FIEs). After performing all of the required calculations, the outputs of the two engines are combined to obtain the final control signal. In other words, the proposed controller consists of four separate controllers, two of them deal with the motion of the cross-beam and the trolley, and the other two controllers handle swing of the payload in both planes. The two main controllers are displacement fuzzy controller and swing fuzzy controller. They obtained good results for damping the swings of payload and also reducing its travel time.

A bang-bang controller is used to track the time optimal trajectories generated for the jib, the trolley, and the cable length. At first, computer simulations showed uncontrolled load swings. The authors attained better results and obtained reduction in the payload swings when they relaxed the constraint on time with a slight increase in the travel time [5].

The authors in [9] could minimize pendulations resulted during the operation of overhead cranes by implementing a fuzzy controller whose control action is distributed between displacement fuzzy controller and swing fuzzy controller. These controllers are fed the displacement and velocity errors with respect to the desired motion profile and they output the forces needed to drive the crane.

The authors in [2] extended the same approach used in [8] to rotary cranes in which both the trolley and jib are allowed to move. They presented three simulation cases for operating crane.

a. Radial mode in which the trolley moves along the jib while the jib is fixed.

b. Rotary mode, the trolley moves along the jib and the jib rotates.

c. The trolley and jib are fixed while the load is given an initial disturbance.

The results from the simulations show that the fuzzy controller is capable of keeping the load-oscillation angles small.

A hybrid command-shaper of two stages, a primary double-step command-shaper cascaded by a virtual feedback system is implemented to generate acceleration commands to minimize swings of a double-pendulum overhead crane. The commands of the primary shaper are modified by the virtual feedback loop and then used to drive the actual crane. This approach succeeded in reducing $95 \%$ of oscillations produced [7].

A hybrid input shaping is presented for anti-sway control of a three degree-of freedom (3-DOF) rotary crane system. They obtained a nonlinear equation of motion in a state space

IJEEI Vol. 5, No. 1, March 2017: $85-98$ 
form for the crane's tower. At first, the authors developed an LQR control for the tower rotation angle of the crane, then they extended the controller to incorporate input shaping techniques for anti-swaying control of the system for another payload and they achieved an acceptable antisway capability [4].

The approach of this study has similar traits to the technique used in [2] but our investigation will be based on some modifications in rules and gains used with fuzzy controllers as will be introduced later.

\section{Model Description and System Parameters}

The model developed in this work is for rotary cranes. It can be described as a trolley that moves radially along a jib which rotates in a horizontal plane. The combined movements of the trolley and the jib enable positioning of the trolley and consequently the load over any point in the work space. The variation in the length of the hoisting cable is important for picking up the load, putting it down, and moving it away from obstacles. It also can be used as a part of the control strategy.

We can briefly describe the crane model (Figure 1) as follows:

1. A tower fixed to a base to prevent any oscillations

2. A jib fixed to the tower is free to rotate around with angle $\gamma(\mathrm{t})$

3. A trolley can travel a distance $r(t)$ (over the length of the jib) from the center of tower. It holds a load $P$ by a cable of variable length $L(t)$.

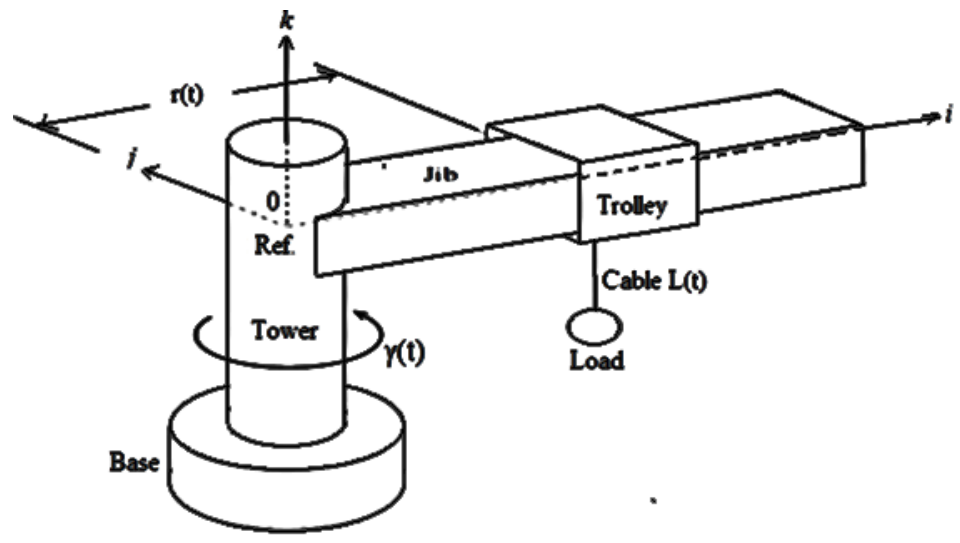

Figure 1: A three dimensional model of a tower crane

The derivation of the mathematical model is explained in [2]. Both of $\gamma(\mathrm{t})$ and $\mathrm{r}(\mathrm{t})$ are to be used as system control inputs. The load is modeled as a point mass. It is also assumed that the mass of the load is very small compared to that of the crane, so that the interaction between the crane dynamics and the load dynamics can be neglected. 


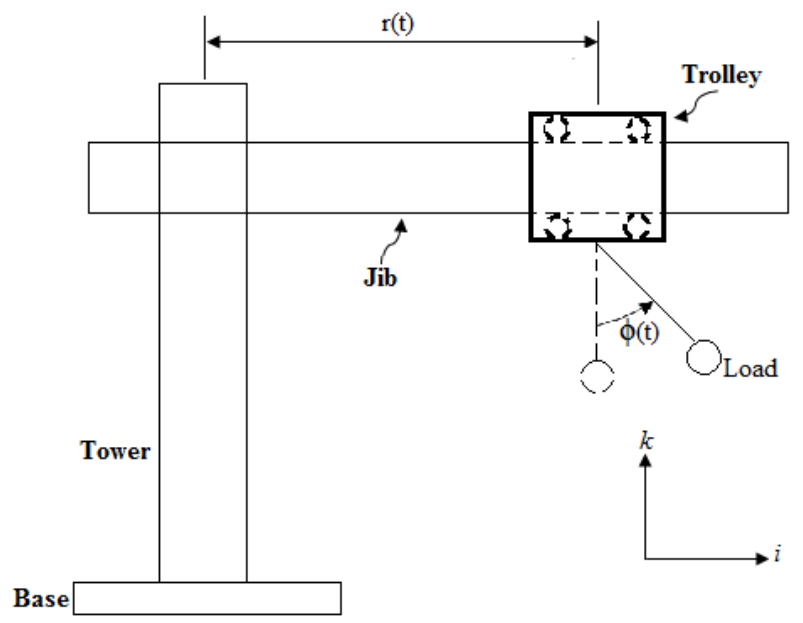

Figure 2: The in-plane angle $\phi$ from the side view of the crane

The two angles, $\phi$ and $\theta$ (shown in Figure 3 ) describe the load swings. Obviously, as shown in Figure 2, the angle $\phi$ is the angle which the line of load makes with the $z$-axis in the $x z$-plane. The out-of-plane angle $\theta$ is the angle which the line of load makes with the xz-plane. Thus, it is clear now that our task is to move the load while keeping the swings angles as small as possible.

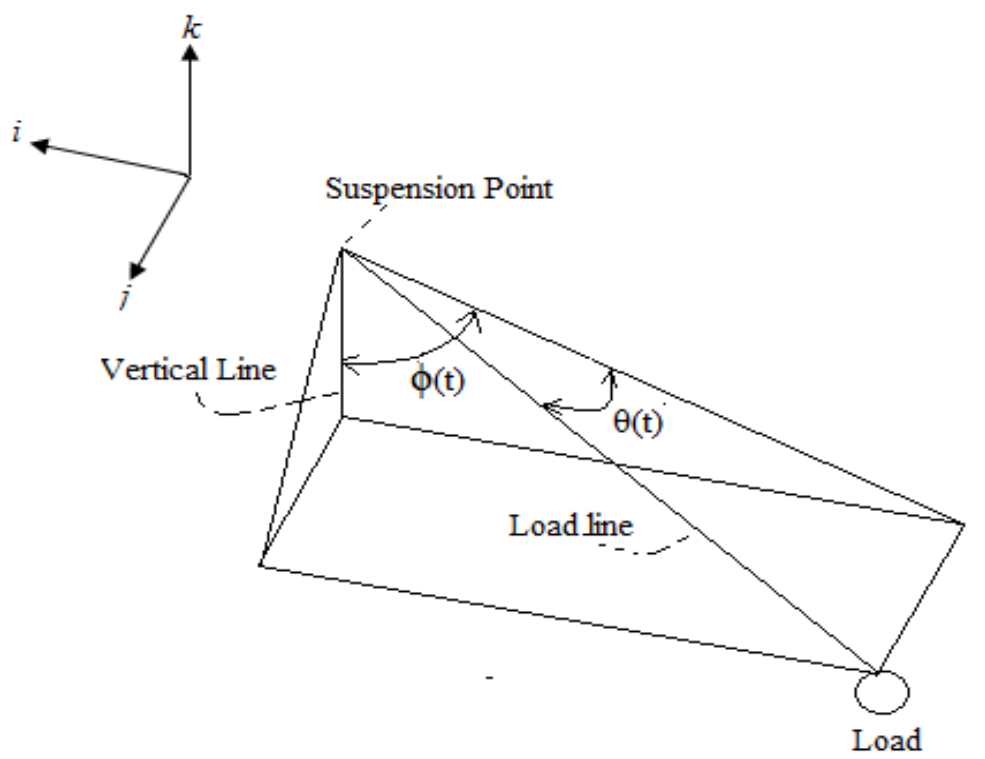

Figure 3: Swinging angles, $\theta(\mathrm{t})$ and $\phi(t)$, of the load held by the trolley 


\section{State-Space Model of the Crane}

The state space model of the crane developed by [2] has 8 states defined as follows:

$$
\begin{array}{llll}
\mathrm{x}_{1}=\theta(\mathrm{t}) & \mathrm{x}_{2}=\phi(\mathrm{t}) & \mathrm{x}_{3}=\mathrm{r}(\mathrm{t}) & \mathrm{x}_{4}=\gamma(\mathrm{t}) \\
\mathrm{x}_{5}=\dot{\theta}(\mathrm{t}) & \mathrm{x}_{6}=\dot{\phi}(\mathrm{t}) & \mathrm{x}_{7}=\dot{\mathrm{r}}(\mathrm{t}) & \mathrm{x}_{8}=\dot{\gamma}(\mathrm{t})
\end{array}
$$

With $U_{1}=\ddot{r}(t)$ and $U_{2}=\ddot{\gamma}(t)$.

Hence,

$$
\begin{aligned}
& \dot{x_{1}}=x_{5} \\
& \dot{x_{2}}=x_{6} \\
& \dot{x_{3}}=x_{7} \\
& \dot{x_{4}}=x_{8} \\
& \dot{x_{7}}=U_{1}=\ddot{r}(t) \\
& \dot{x_{8}}=U_{2}=\ddot{\gamma}(t)
\end{aligned}
$$

And

$$
\begin{aligned}
& \dot{\mathrm{x}_{5}}=-\frac{1}{2 \mathrm{~L}}\left(2 \mathrm{gcos}_{2} \sin \mathrm{x}_{1}+4 \mathrm{x}_{7} \mathrm{x}_{8} \cos \mathrm{x}_{1}-\mathrm{Lx}_{8}{ }^{2} \sin 2 \mathrm{x}_{1} \cos ^{2} \mathrm{x}_{2}-2 \mathrm{x}_{3} \mathrm{x}_{8}{ }^{2} \sin \mathrm{x}_{1} \sin \mathrm{x}_{2}-\right. \\
& \left.4 \mathrm{Lx}_{6} \mathrm{X}_{8} \cos \mathrm{X}_{2} \cos ^{2} \mathrm{x}_{1}+\mathrm{Lx}_{6}{ }^{2} \sin 2 \mathrm{x}_{1}+2 \sin \mathrm{x}_{1} \sin \mathrm{X}_{2} \mathrm{U}_{1}+2 \mathrm{x}_{3} \cos \mathrm{X}_{1} \mathrm{U}_{2}-2 \mathrm{Lsin} \mathrm{X}_{2} \mathrm{U}_{2}\right) \\
& \dot{\mathrm{x}}_{6}=-\frac{1}{\mathrm{~L} \cos \mathrm{x}_{1}}\left(\mathrm{ggin}_{2}+\mathrm{x}_{3} \mathrm{x}_{8}{ }^{2} \cos \mathrm{x}_{2}-\mathrm{Lx}_{8}{ }^{2} \sin \mathrm{x}_{2} \cos \mathrm{x}_{1} \cos \mathrm{x}_{2}+2 \mathrm{Lx}_{5} \mathrm{x}_{8} \cos \mathrm{x}_{1} \cos \mathrm{x}_{2}-\right.
\end{aligned}
$$

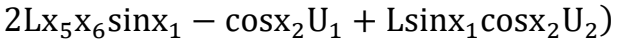

\section{Fuzzy Controller Design}

In this section, the Simulink model for the system described by equations 3.1 to 3.8 is developed for the tower crane. Also, a fuzzy controller (similar to the controller used in [2] is developed as follows.

Two main Fuzzy Logic controllers, FLCs, are employed in the work; each one is created using two fuzzy inference engines (FIEs). The first is a radial controller that handles transfer motion of the trolley over the jib. The second is a rotational controller that handles rotational motion of the jib around the tower axis. As we mentioned before, $\gamma(\mathrm{t})$ and $\mathrm{r}(\mathrm{t})$ are the inputs to the system and hence they are used to control the system behavior, i.e. to move the payload while keeping $\phi$ and $\theta$ as small as possible). The four FIEs are created as follows.

\subsection{FIE-1: Radial tracking FIE}

Inputs: The fuzzified radial distance error $\widetilde{\mathrm{E}}_{\mathrm{r}}(\mathrm{t})$ (shown in Figure 4), and its derivative $\overrightarrow{\mathrm{E}}_{\mathrm{r}}(\mathrm{t})$ (shown in Figure 5). Where, $\mathrm{E}_{\mathrm{r}}(\mathrm{t})=\mathrm{r}_{d}(\mathrm{t})-\mathrm{r}_{\mathrm{a}}(\mathrm{t}), \grave{\mathrm{E}}_{\mathrm{r}}(\mathrm{t})=\grave{\mathrm{r}}_{\mathrm{d}}(\mathrm{t})-\grave{\mathrm{r}}_{\mathrm{a}}(\mathrm{t}), \mathrm{r}_{d}(\mathrm{t})$ is the desired radial distance (of the trolley along the jib) and $r_{a}(t)$ is the actual radial distance. We started simulation by setting $\mathrm{r}_{\mathrm{d}}(\mathrm{t})$ to zero. $6)$.

Output: The defuzzification of radial tracking acceleration $\ddot{\mathrm{r}}_{\text {Track }}(\mathrm{t}$ ) (shown in Figure 


\subsection{FIE-2: Radial oscillation damping FIE:}

Inputs: The fuzzified in-plane angle $\widetilde{\phi}(\mathrm{t})$ (shown in Figure 7) and its derivative $\grave{\phi}(\mathrm{t})$ (shown in Figure 8). Figure 9).

Output: The defuzzification of radial correction acceleration $\ddot{\mathrm{r}}_{\text {Correction }}(\mathrm{t})$ (shown in

\subsection{FIE-3: Rotational tracking FIE}

Inputs: The fuzzified rotational angle error $\widetilde{\mathrm{E}}_{\gamma}(\mathrm{t})$ (shown in Figure 10) and its derivative $\breve{\mathrm{E}}_{\gamma}(\mathrm{t})$ (shown in Figure 11). Where, $\mathrm{E}_{\gamma}(\mathrm{t})=\gamma_{\mathrm{d}}(\mathrm{t})-\gamma_{\mathrm{a}}(\mathrm{t}), \grave{\mathrm{E}}_{\gamma}(\mathrm{t})=\grave{\gamma}_{\mathrm{d}}(\mathrm{t})-\grave{\gamma}_{\mathrm{a}}(\mathrm{t})$, $\gamma_{d}(t)$ is the desired rotational angle (that the jib traces around the tower axis) and $\gamma_{a}(t)$ is the actual rotational angle. We started simulation by setting $\gamma_{d}(t)$ to zero. Figure 12).

Output: The defuzzification of rotational tracking acceleration $\ddot{\gamma}_{\text {Track }}(\mathrm{t})$ (shown in

\subsection{FIE-4: Rotational oscillation damping FIE}

Inputs: The fuzzified out-of-plane angle $\tilde{\theta}(\mathrm{t})$ (shown in Figure 13) and its derivative Ө̃̀( $\mathrm{t}$ ) (shown in Figure 14). in Figure 15).

Output: The defuzzification of rotational correction acceleration $\ddot{\gamma}_{\text {correction }}(\mathrm{t})$ (shown

The output of radial tracking FIE, $\ddot{\mathrm{r}}_{\text {Tracking }}(\mathrm{t})$, and radial oscillation damping FIE, $\ddot{r}_{\text {Correction }}(t)$, are combined together to give $U_{1}$ according to the relation: $\ddot{r}_{\text {Refference }}(t) \equiv U_{1}=$ $(1-\mathrm{C}) \ddot{\mathrm{r}}_{\text {Tracking }}(\mathrm{t})+\mathrm{C} \ddot{\mathrm{r}}_{\text {Correction }}(\mathrm{t})$

The output of rotational tracking FIE, $\ddot{\gamma}_{\text {Tracking }}(\mathrm{t})$, and rotational oscillation damping FIE, $\ddot{\gamma}_{\text {Correction }}(t)$, are combined together to give $U_{2}$ according to the relation: $\ddot{\gamma}_{\text {Refference }}(t) \equiv$ $\mathrm{U}_{2}=(1-\mathrm{M}) \ddot{\gamma}_{\text {Tracking }}(\mathrm{t})+\mathrm{M} \ddot{\gamma}_{\text {Correction }}(\mathrm{t})$

Where the determination of the parameters $M$ \& $C$ help improve the system response as will be introduced latter.

The fuzzy sets used here (shown in figures from Figure 4 to Figure 15) are similar to those used by [2].

The four FIEs are Programmed (the fis-file is created for each engine using its own fuzzy sets, rules in tables $1-4$ and loading the fis file inside the FIE) and set $L=1 \mathrm{~m}$, $\mathrm{g}=9.8 \mathrm{~m} / \mathrm{sec} 2$.

Table 1: Rules for radial tracking FIE

\begin{tabular}{|c|c|c|c|c|c|c|c|c|}
\hline & & \multicolumn{7}{|c|}{$\tilde{\tilde{\mathbf{E}}}_{\mathbf{r}}(\mathbf{t})$} \\
\hline & & PL & PM & PS & Z & NS & NM & $\mathrm{NL}$ \\
\hline \multirow{7}{*}{$\widetilde{\mathbf{E}}_{\mathbf{r}}(\mathbf{t})$} & PL & $\mathrm{PL}$ & PM & PM & PM & PS & PS & $\mathrm{Z}$ \\
\hline & PM & PM & PM & PM & PS & PS & Z & NS \\
\hline & PS & PM & PM & PS & PS & Z & NS & NS \\
\hline & Z & PM & PS & PS & Z & NS & NS & NM \\
\hline & NS & PS & PS & Z & NS & NS & NM & NM \\
\hline & NM & PS & Z & NS & NS & NM & NM & NM \\
\hline & NL & $Z$ & NS & NS & NM & NM & NM & $\mathrm{NL}$ \\
\hline
\end{tabular}

IJEEI Vol. 5, No. 1, March 2017: $85-98$ 


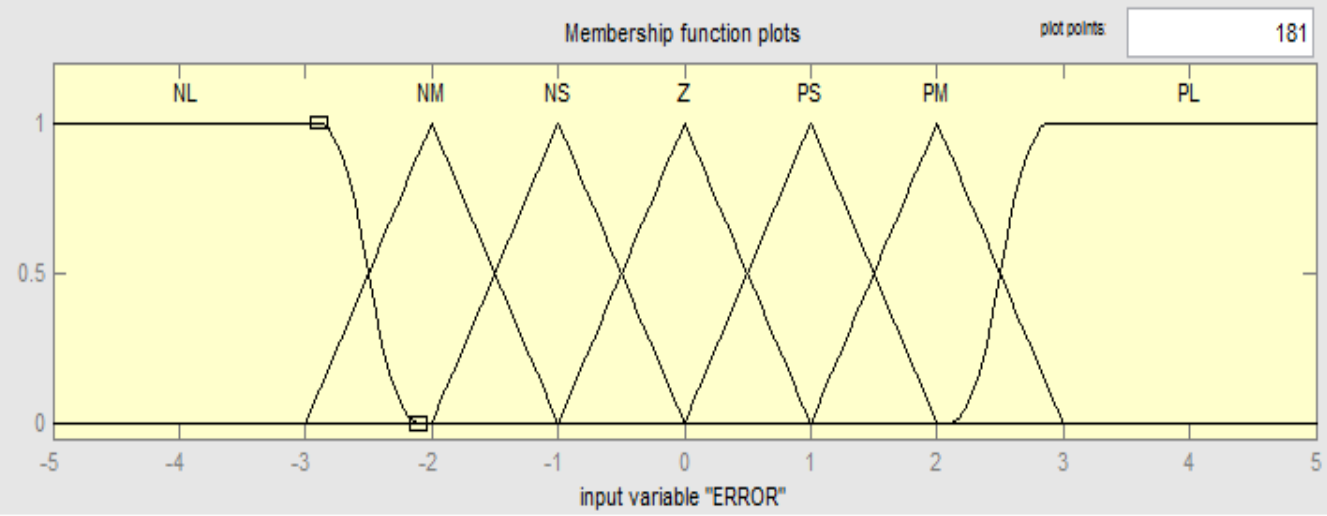

Figure 4: Fuzzy sets of radial distance error $E_{r}(t)$

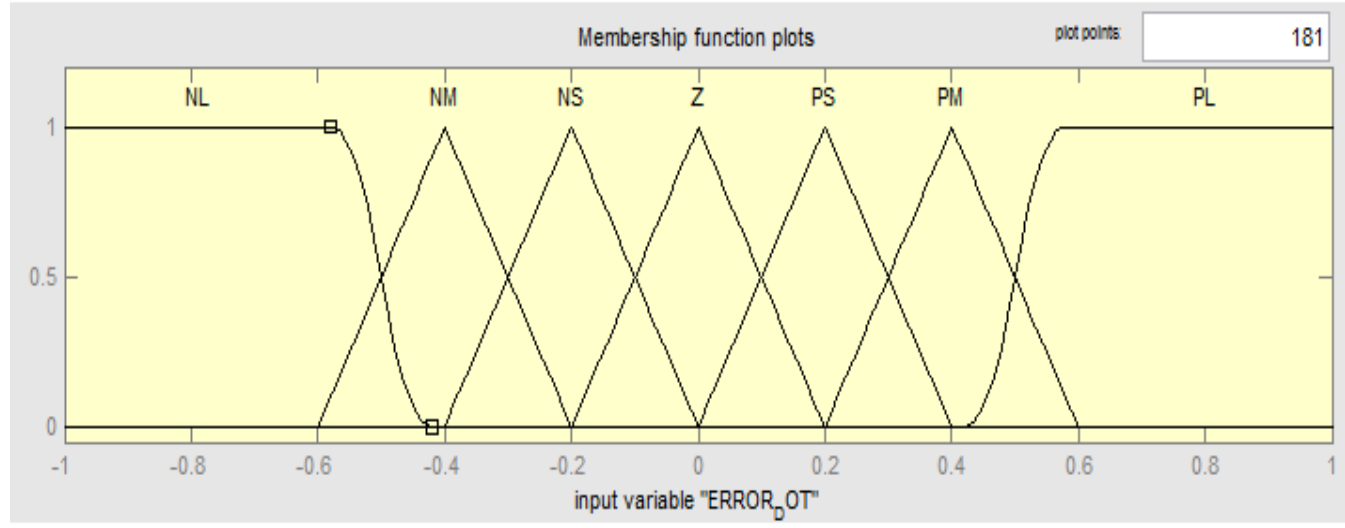

Figure 5: Fuzzy sets of the derivative of radial distance error $\grave{E}_{\mathrm{r}}(\mathrm{t})$

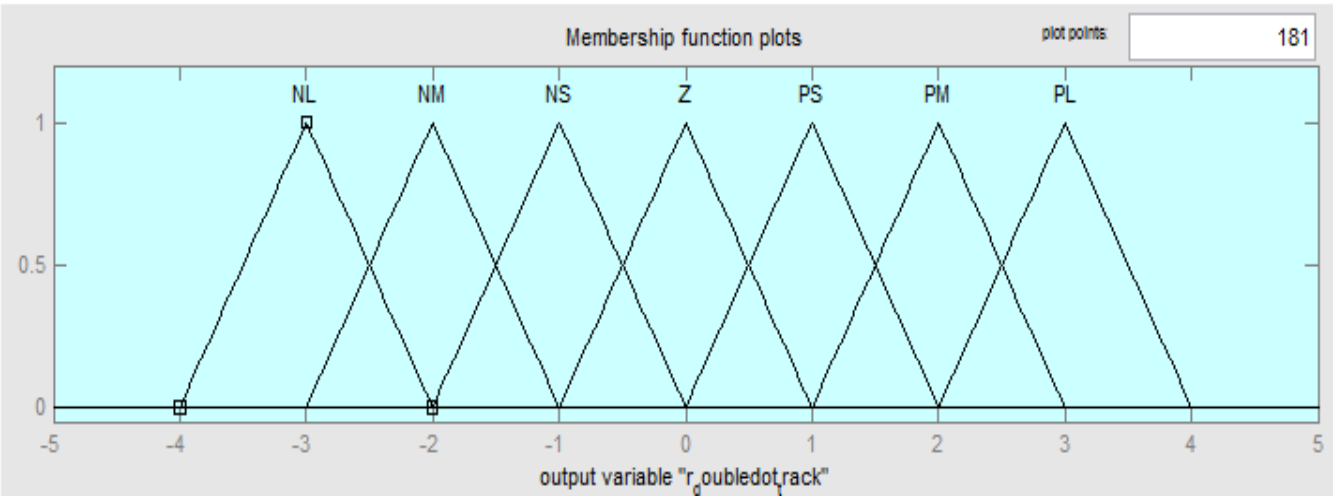

Figure 6: Fuzzy sets of radial tracking acceleration $\ddot{\mathrm{r}}_{\text {Track }}(\mathrm{t})$

Table 2: Rules for radial oscillation damping FIE

\begin{tabular}{|c|c|c|c|c|c|c|c|c|}
\hline & & \multicolumn{7}{|c|}{$\widetilde{\phi}(\mathrm{t})$} \\
\hline & & $\mathrm{PL}$ & PM & P & Z & NS & NM & $\mathrm{NL}$ \\
\hline & $P$ & $\mathrm{NM}$ & NS & NS & $Z$ & PS & $\mathrm{PM}$ & $\mathrm{PM}$ \\
\hline 市(t) & $Z$ & Z & Z & Z & Z & Z & Z & Z \\
\hline & & & & & & & & \\
\hline
\end{tabular}




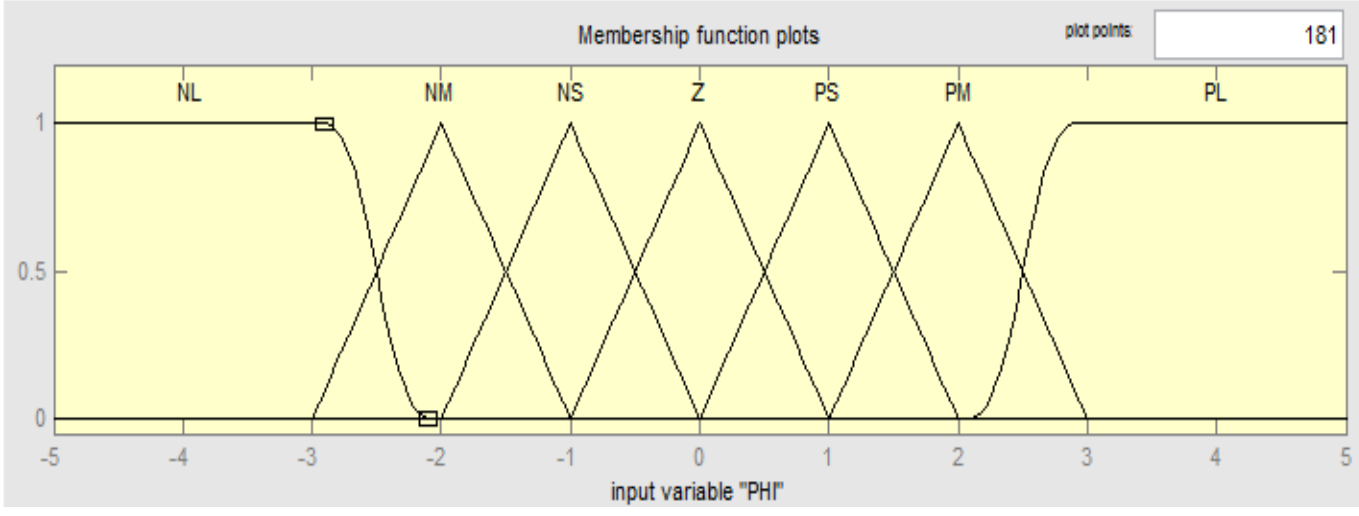

Figure 7: Fuzzy sets of the in-plane angle $\phi(t)$

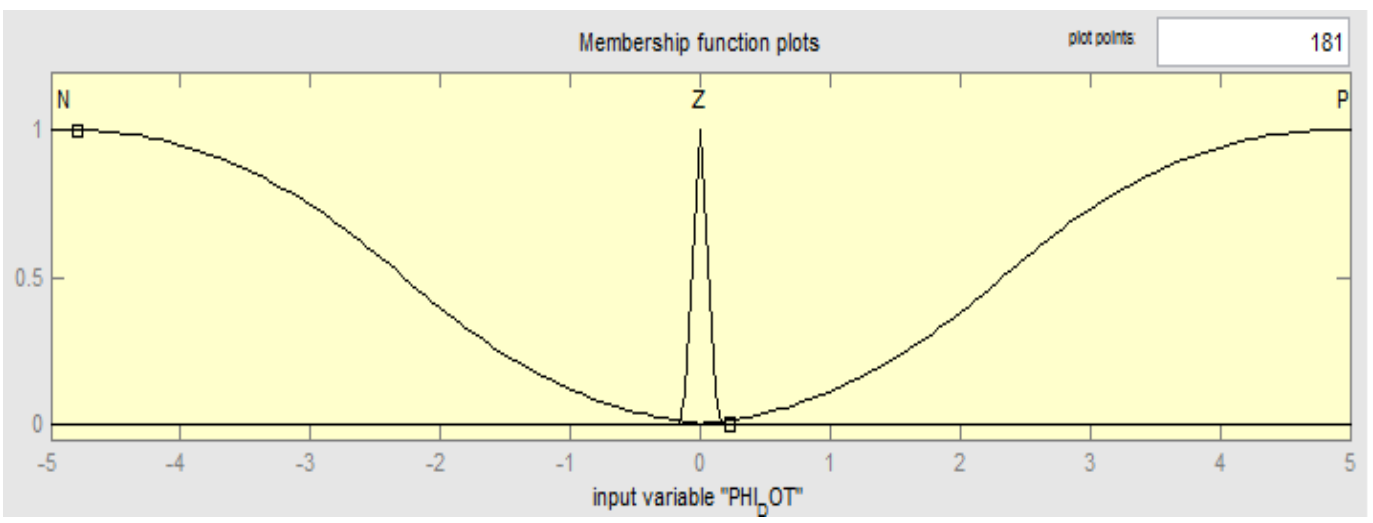

Figure 8: Fuzzy sets of the derivative of in-plane angle $\grave{\phi}(\mathrm{t})$

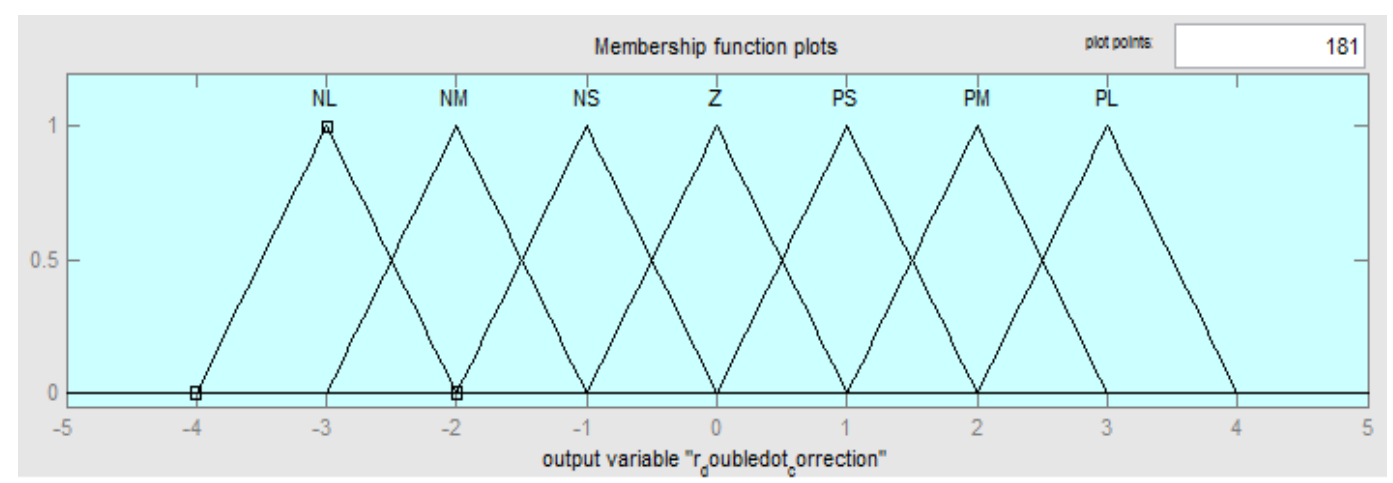

Figure 9: Fuzzy sets of radial correction acceleration $\ddot{\mathrm{r}}_{\text {Track }}(\mathrm{t})$

Table 3: Rules for rotational tracking FIE

\begin{tabular}{ccccccccc} 
& & $P L$ & $P M$ & $P S$ & $Z$ & $N S$ & $N M$ & $N L$ \\
\hline \multirow{6}{*}{$\widetilde{E}_{\gamma}(t)$} & $P L$ & $P L$ & $P M$ & $P M$ & $P M$ & $P S$ & $P S$ & $Z$ \\
& PM & PM & PM & PM & PS & PS & Z & NS \\
& PS & PM & PM & PS & PS & Z & NS & NS \\
& Z & PM & PS & PS & Z & NS & NS & NM \\
& NS & PS & PS & Z & NS & NS & NM & NM \\
& NM & PS & $Z$ & NS & NS & NM & NM & NM \\
& NL & Z & NS & NS & NM & NM & NM & NL \\
\hline
\end{tabular}




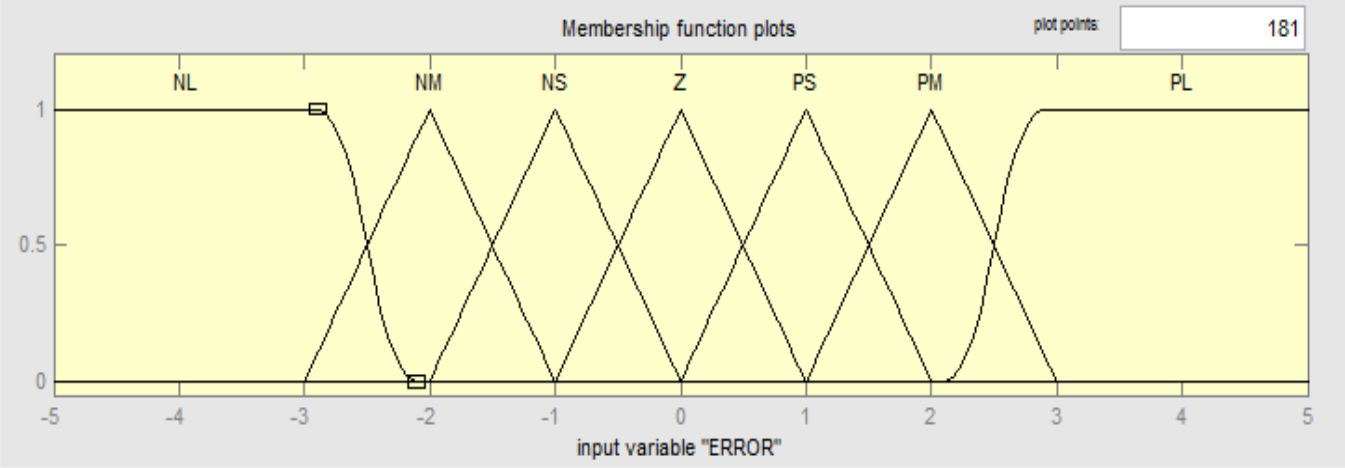

Figure 10: Fuzzy sets of rotational angle error $E_{\gamma}(t)$

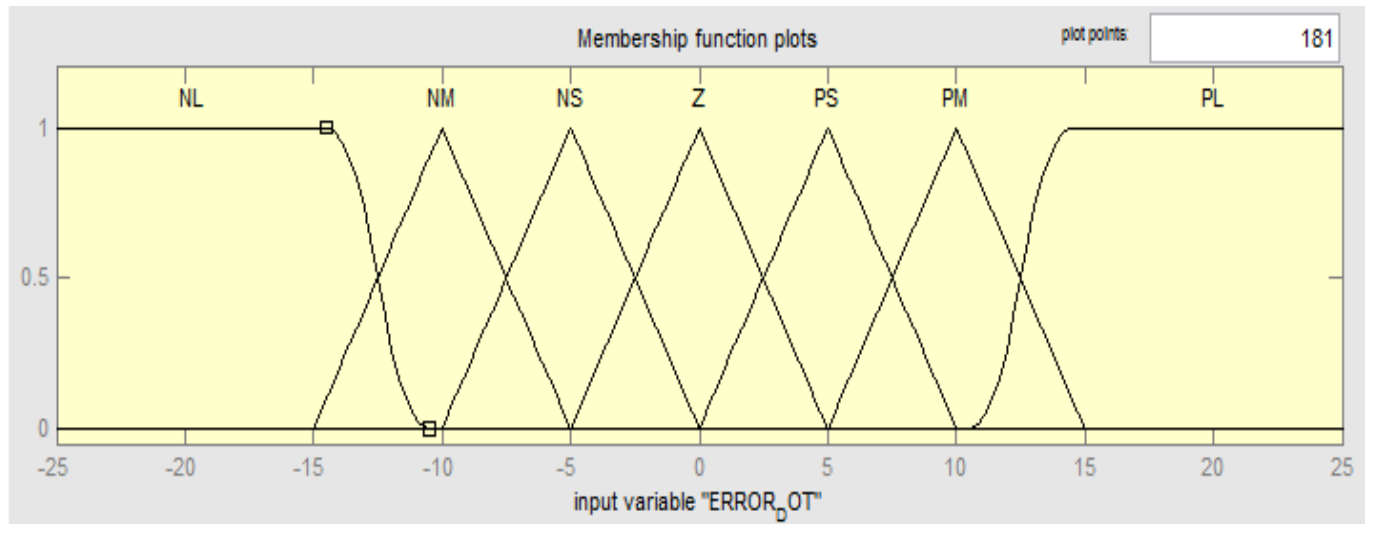

Figure 11: Fuzzy sets of the derivative of rotational angle error $\grave{E}_{\gamma}(t)$

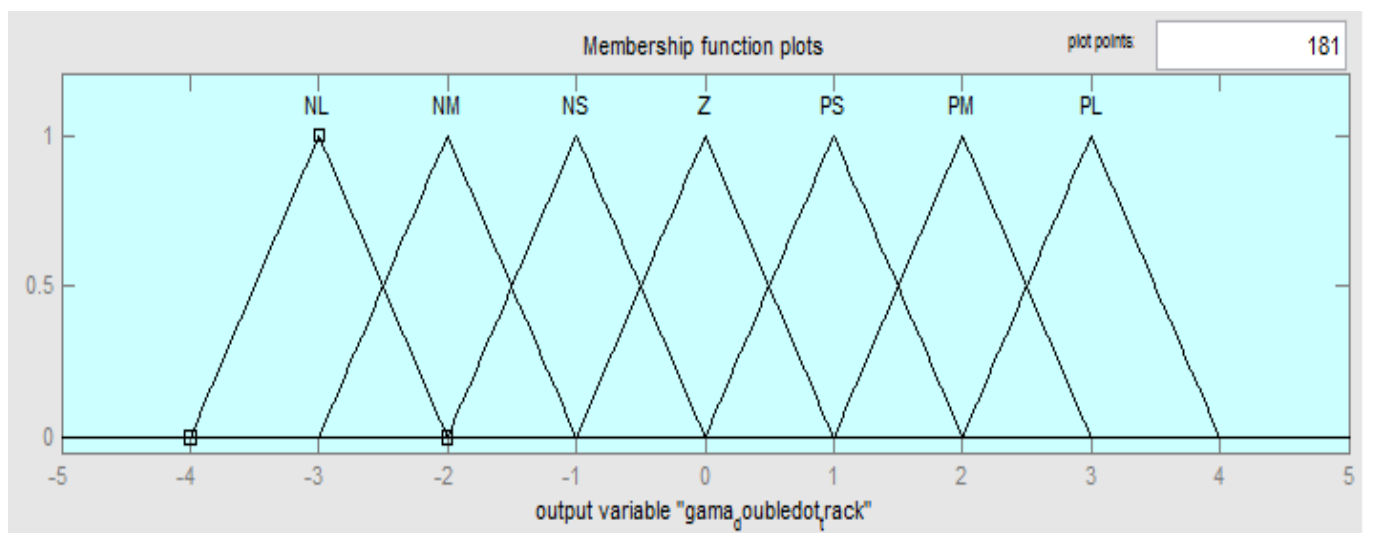

Figure 12: Fuzzy sets of rotational tracking acceleration $\ddot{\gamma}_{\text {Track }}(\mathrm{t})$

Table 4: Rules for rotational oscillation damping FIE

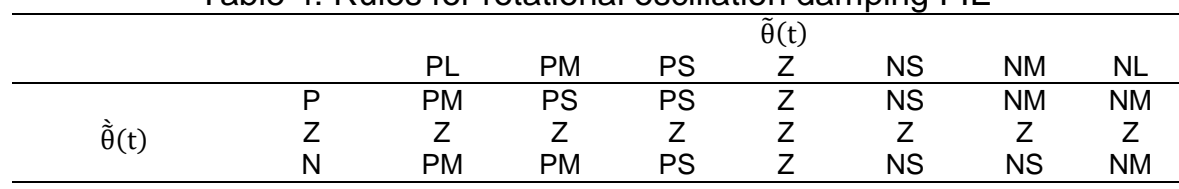




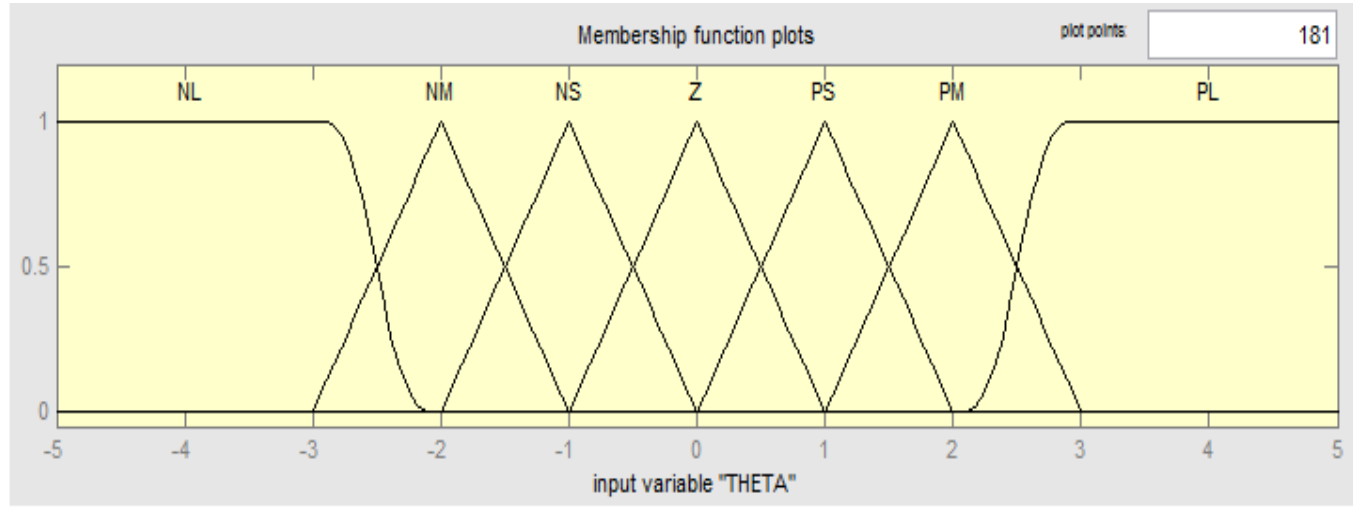

Figure 13: Fuzzy sets of the out-of-plane angle $\theta(t)$

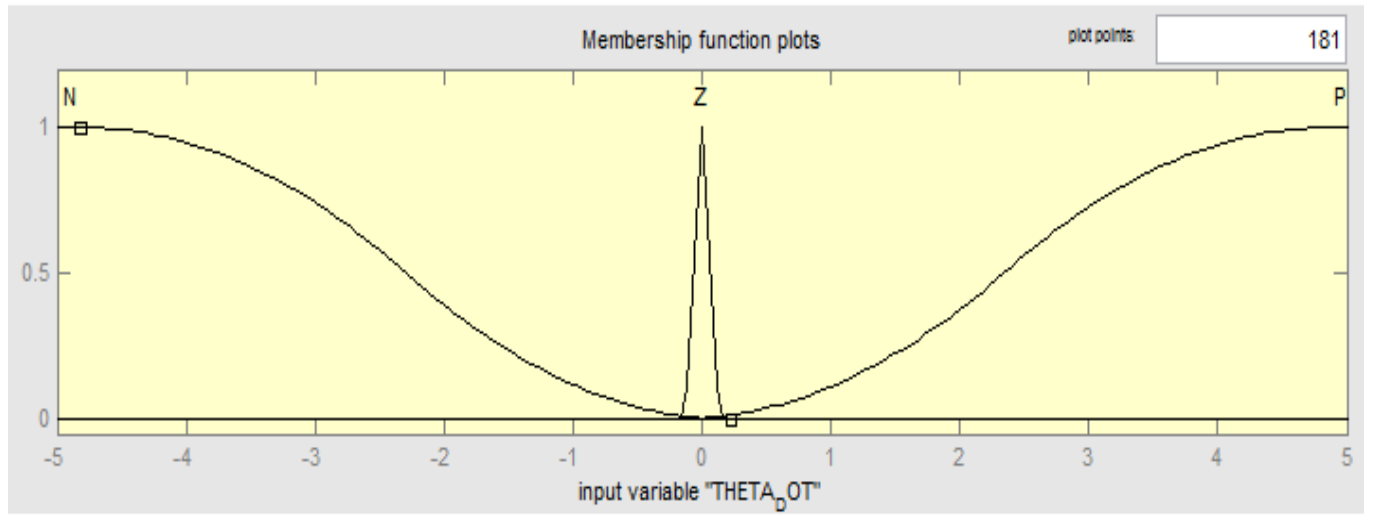

Figure 14: Fuzzy sets of the derivative of out-of-plane angle $\grave{\theta}(\mathrm{t})$

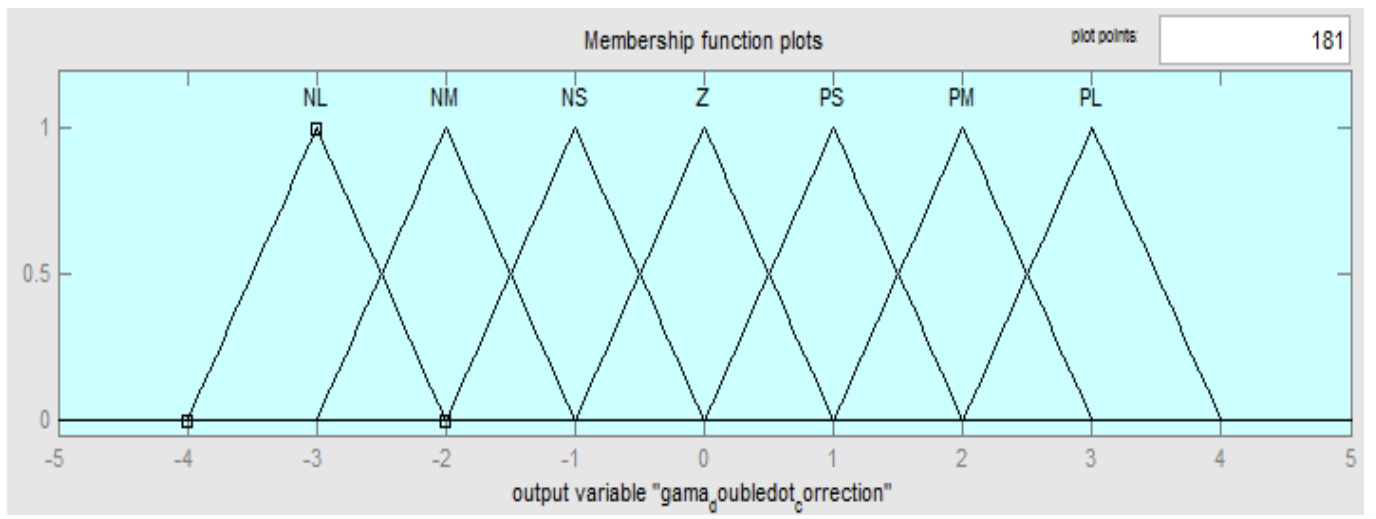

Figure 15: Fuzzy sets of rotational correction acceleration $\ddot{\gamma}_{\text {Track }}(t)$ 


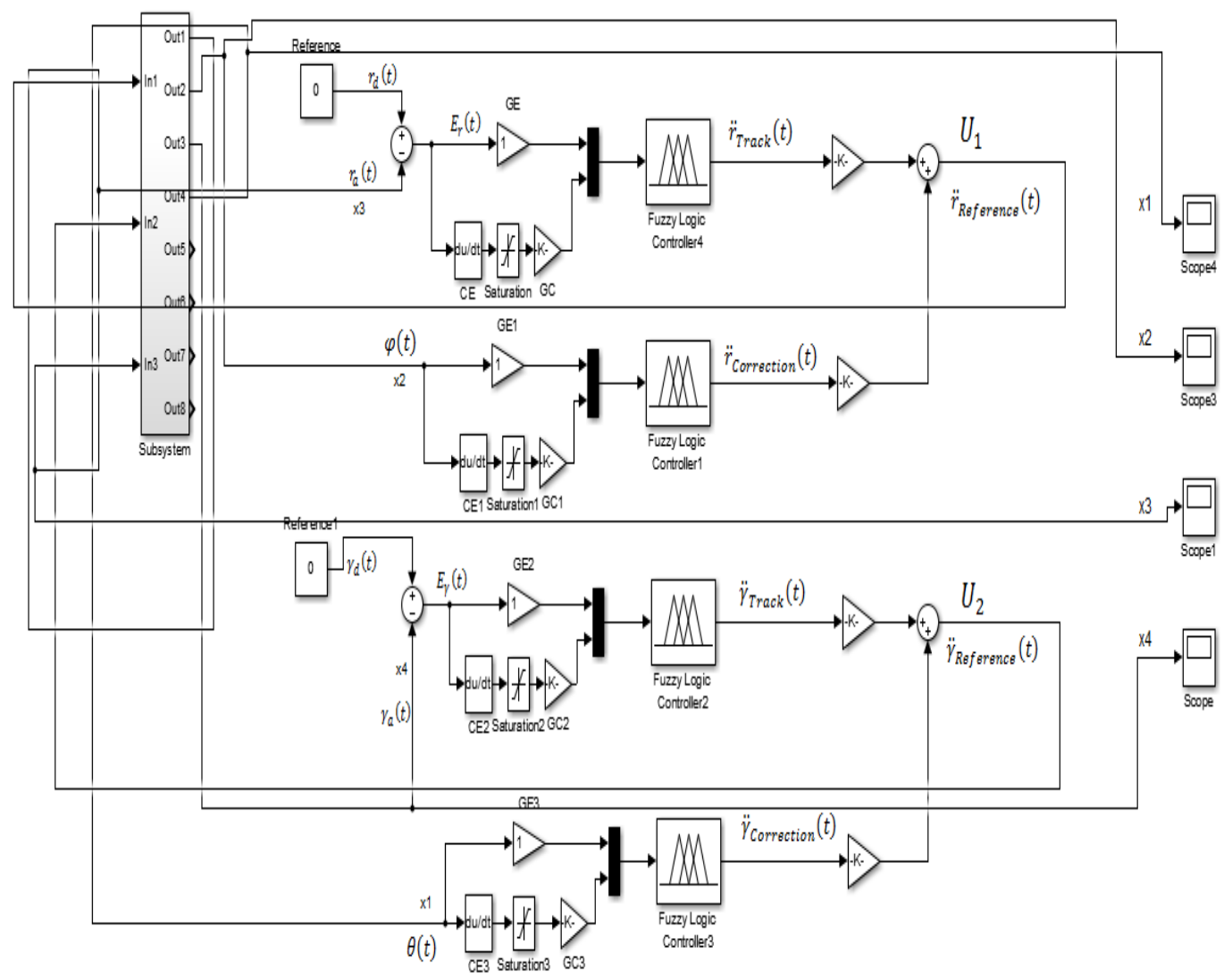

Figure 16: Simulink model for the controlled crane model using fuzzy control

\section{Simulation results:}

At first, we didn't use control, i.e. applied open-loop control, and the system response was too oscillatory (as shown in Figure 17).
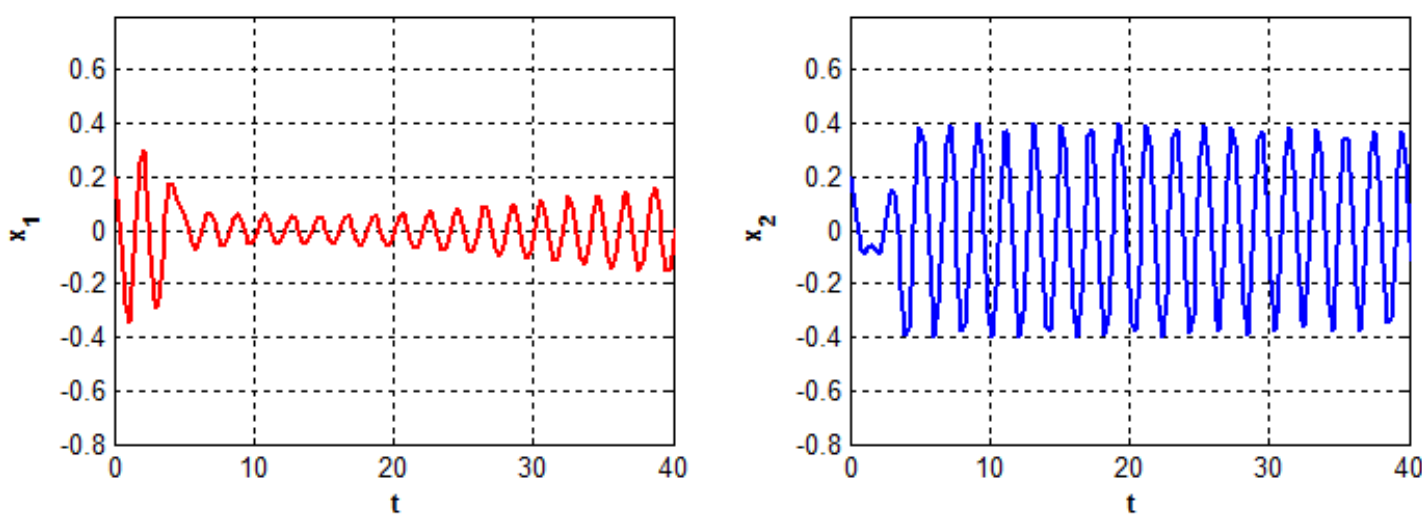

Figure 17: The response in case of open-loop control. Where, $t$ is in seconds and $\mathrm{x} 1$ : out-of-plane oscillation angle $\theta(\mathrm{t})$ and $\mathrm{x} 2$ : in-plane oscillation angle $\phi(\mathrm{t})$ 
After applying fuzzy control (and using the optimal values for the parameters $C$ \& $M$ to be 0.66 and 0.67 respectively) and running the model for 50 seconds, we noted a reduction in oscillation angles more than those got in [2] as shown in Figures 18 and19 compared to Figure 20.
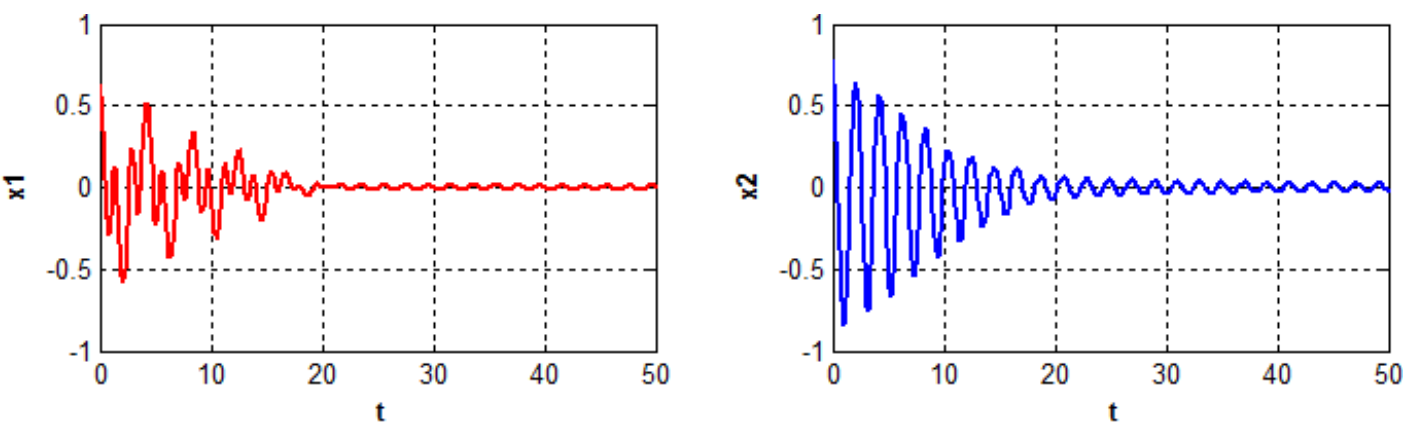

Figure 18: The response in case of using fuzzy controller and running the model for 50 seocnds. Where, $t$ is in seconds.

$x 1$ : out-of-plane oscillation angle $\theta(t)$ and $x 2$ : in-plane oscillation angle $\phi(t)$

Also, running the model for 100 seconds yields the results shown in Figure 19:
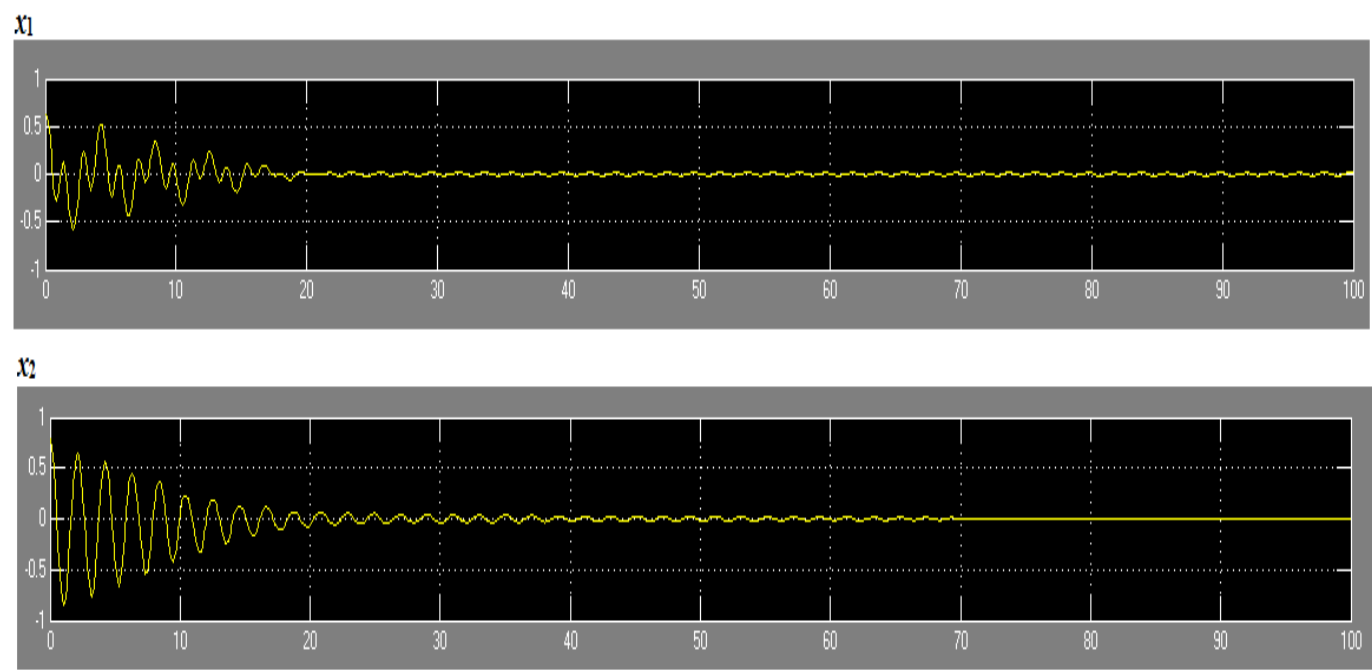

Figure 19: The response in case of using fuzzy controller and running the model for 100 seconds. 

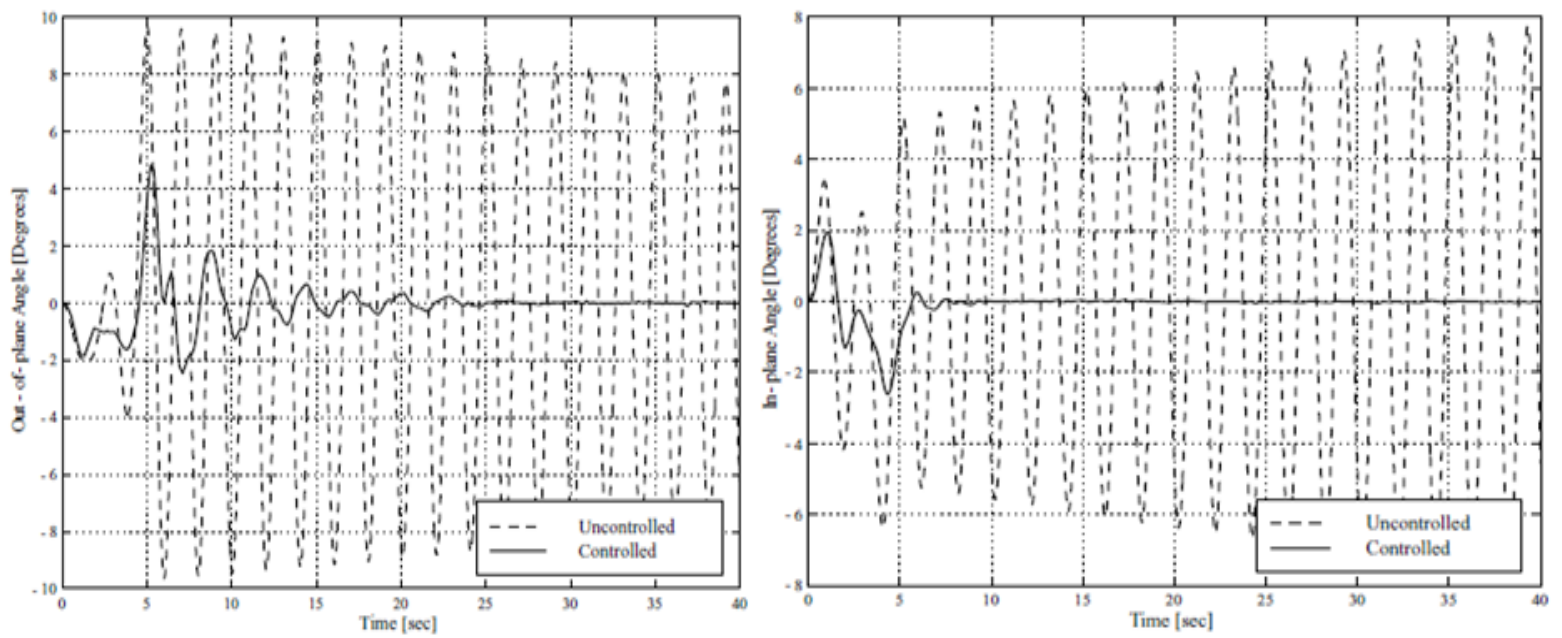

Figure 20: The responses got in [2]

\section{Conclusion}

By distributing the controller task over two main controllers; each of them, deals with few certain variables instead of all variables at once and each one consists of two FIEs whose outputs are combined to give the final control signal to the system, the task of automating the crane model becomes simpler. We showed, using simulation, that the fuzzy logic controller can control the operations of tower crane and minimize the swings resulted from the nature of pendulum-like end line attached to its trolley by the good choice of the fuzzy rules and the good combination of the parameters $C \& M$. The performance of fuzzy controller was simulated using the nonlinear model of the crane and using the FLC block in the Simulink of MATLAB. From simulation results, satisfactory vibration reduction of the system has been achieved using the proposed method, even in case of the oscillations at the beginning of loading the crane, i.e. damp the initial kicks in the in-plane and out-of-plane angles and hence the controller still control the operation of crane. Also, the controller could minimize any swings resulted form any disturbances during the operation of crane.

\section{Acknowledgement}

The first author would like to thank Drs. Tayel E. Dabbous and Dr. Helmy El-Zoghby for their guidance.

\section{References}

[1] Al-Mousa AA. Control of Rotary Cranes Using Fuzzy Logic and Time-Delayed Position Feedback Control. Master Thesis, Electrical and Computer Department, Virginia Polytech Institute. 2000.

[2] Al-Mousa AA, Nayfeh AH and Kachrooc P. (2003) Control of Rotary Cranes Using Fuzzy Logic and Time-Delayed Position Feedback Control. Journal of Shock and Vibration 10: 81-95.

[3] Blajer W, Kołodziejczyk K. (2006) Dynamics and control of rotary cranes executing a load prescribed motion. Journal of theoretical and applied mechanics: 929-948.

[4] Ezuan R, Samin, Mohamed Z, Jalani J, and Ghazali R. A Hybrid Controller for Control of a 3-DOF Rotary Crane System. In: First International Conference on Artificial Intelligence, Modelling \& Simulation. 2013: 167-171.

[5] Golafshani AR, Aplevich JD. Computation of Time-Optimal Trajectories for Tower Cranes. In: IEEE Conference on Control Applications conference. Albany, NY. 1995: 1134-1139.

[6] Kaur A, Priyahansha, Kumari S, and Singh T. Position Control of Overhead Cranes Using fuzzy Controller. International Journal of Advanced Research in Electrical, Electronics and Instrumentation Engineering 3. 2014 
[7] Masoud Z, Alhazza K, Abu-Nada E, and Majeed M. A Hybrid Command-Shaper for Double-Pendulum Overhead Cranes. Journal of Vibration and Control 20. 2012: 24-37.

[8] Nally, M.J. and Tarbia, M.B. Design of a Fuzzy Logic Controller for Swing-Damped Transport of an Overhead Crane Payload. ASME Dynamic Systems and Control Division conference DSC 58. 1994: 389-398.

[9] Nalley, M.J. and Trabia, M.B. Control of Overhead Cranes Using A Fuzzy Logic Controller. Journal of Intelligent and Fuzzy Systems 8. 2000: 1-18.

[10] Parker GG, Petterson B, Dohrmann CR, Robinett RD. Vibration Suppression of Fixed-Time Jib Crane Maneuvers. SPIE Symposium on the Smart Structures and Materials Conference 2447. 1995: 131140.

[11] Parker GG, Petterson B, Dohrmann C, Robinett RD. Command Shaping for Residual Vibration Free Crane Maneuvers. American Control conference. Seattle, Washington. 1995: 934-938.

[12] Parker GG, Petterson B, Dohrmann C, Robinett RD. Operator in-the-Loop Control of Rotary Cranes. SPIE Symposium on the SmartStructures and Materials Conference 2721.1996: 364-372.

IJEEI Vol. 5, No. 1, March 2017: $85-98$ 